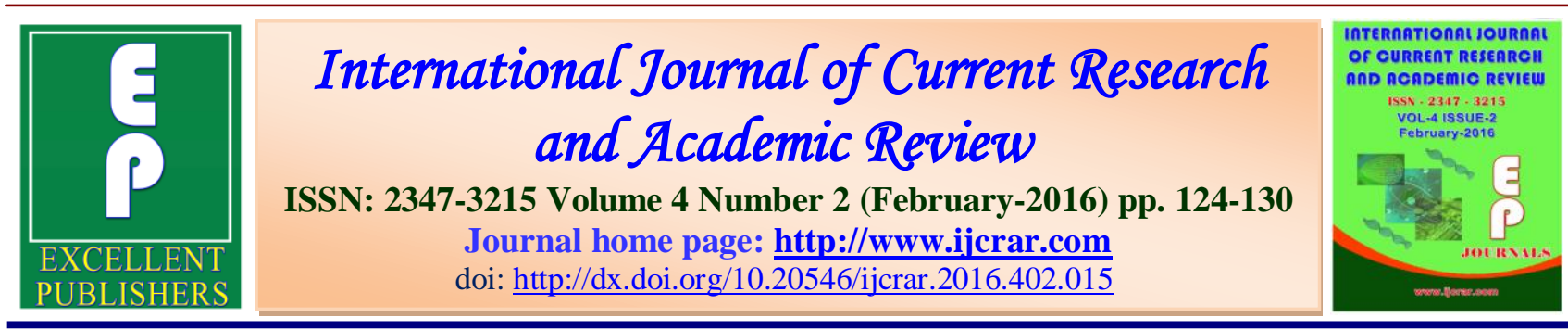

\title{
Iron Carboxymaltose: A Safe and Effective Molecule to Combat Anemia in Pregnancy
}

\author{
Ruchika Garg $^{1 *}$, Asha Nigam ${ }^{1}$, Prabhat Agrawal', Ashwini Nigam² and Rachna Agrawal ${ }^{2}$ \\ ${ }^{1}$ Department of OBS and Gynaecology, SN Medical College, Agra, India \\ ${ }^{2}$ Department of Medicine, SN Medical College, Agra, India
}

*Corresponding author

\begin{tabular}{|l|l|}
\hline \multirow{2}{*}{$\begin{array}{l}\text { KEYWORDS } \\
\text { Carboxymaltose, }\end{array}$} & A B S T R A C T \\
\cline { 2 - 2 } $\begin{array}{l}\text { Premia in } \\
\text { A large group of pregnant females attend antenatal clinics at 28-32 wks } \\
\text { of pregnancy when they already become anaemic. Most of the pregnant } \\
\text { women do not consume oral iron (56\%) because of side effects, only } \\
10 \% \text { women consume correctly. The present prospective study is } \\
\text { consistent with other studies that ferric carboxy maltose administration } \\
\text { in the second and third trimester of pregnancy is likely to be safe and } \\
\text { effective the mean haemoglobin level achieved in the intravenous iron } \\
\text { ferric carboxy maltose was significantly higher than iron sucrose group } \\
\text { the simple FCM dosing regime was associated with greater patient } \\
\text { compliance compared with iron sucrose . }\end{array}$
\end{tabular}

\section{Introduction}

Anemia is one of the world's leading cause of disability and thus one of the most serious global public health problems. Anemia affects nearly half of the pregnant woman in the world. Globally anaemia affects 1.62 billion people which correspond to $24.8 \%$ of the population. Prevalence of anaemia is highest in south Asian countries in the world. It is estimated that half of the global maternal deaths due to anaemia occur in south Asian countries.
India alone contributes $50 \%$ of global maternal deaths due to anemia(1). It is estimated that in India $50 \%$ of population suffering from anemia. About 20-40\% of maternal deaths in India are due to anemia and one in every 2 Indian women (56\%) suffers from some form of anaemia(2). In Indian $41.8 \%$ pregnant women are affected from anaemia which is the underlying cause of maternal mortality andprenatal mortality (3). 
The low dietary intake of iron and folic acid coupled with poor bioavailability of iron is the major factor responsible for very high prevalence of anaemia in the $\operatorname{India}(4,5)$. Iron deficiency anemia is a common nutritional deficiency amongst women of childbearing age. Pregnant women with IDA are associated with significant prenatal morbidity and mortality. Women with IDA are at increased risk of preterm birth, fetal growth restriction, intra uterine fetal death and low apgar score and infections. According to $\mathrm{WHO}$, anemia in pregnancy is defined when the hemoglobin concentration inperipheral blood is less than $11 \mathrm{gm} / \mathrm{dl}$. Hemoglobin level $9-11 \mathrm{gm} / \mathrm{dl}$ is mild, 7-9 $\mathrm{gm} / \mathrm{dl}$ is moderate and less than $7 \mathrm{gm} / \mathrm{dl}$ is severe anaemia (6).

A large group of pregnant females attend antenatal clinics at 28-32 wks of pregnancy when they already become anaemic. Most of the pregnant women do not consume oral iron $(56 \%)$ because of side effects, only $10 \%$ women consume correctly. Iron deficiency anemia is preventable and treatable, our aim is to replenish the iron stores during antenatal period and during labour and enhances the hemoglobin level to produce the positive effect of the health of mother and infant.

Oral iron is the best treatment of choice for the majority of patients with iron deficiency anemia in pregnancy. However oral supplementation has some disadvantages like poor absorption, poor compliance and significant side effects of gastrointestinal $\operatorname{tract}(7)$.

Parenteral iron helps in restoring iron stores faster and more effectively than oral iron. Intravenous iron preparations offer an alternative approach in pregnant women with moderate to severe anaemia which are having in tolerance of oral iron preparation.
The incidence of anaphylaxis and other adverse reaction with i.v iron sucrose is markedly lowered with ferric carboxymaltose injection. Also reduces the multiple dose infusion by giving intravenous ferric carboxymaltose. FCM has a neutral $\mathrm{pH}$ (5.0-7.0) and physiological osmolarity , which makes the possible to administer its higher single dose over short time periods than other parenteral preparations(8). Because it does not contain dextran, chances of anaphylaxis is very low, so test dose is not required.

There is very limited clinical studies regarding the use of FCM during pregnancy So our aim of study to use of injection ferric carboxymaltose in the treatment of pregnancy with anaemia and to improve the quality of life and to withstand the stress of labour.

\section{Materials and Methods}

This comparative study was conducted in the department of obstetrics and Gynaecology, S.N Medical College, Agra over a period of 1 Year from July 2014 to July 2015.

Total 100 antenatal women with Iron deficiency anemia attending the outpatient department between the 28-34 wks of gestation age were included in our study .Cases were randomly distributed into two groups consisting of 50 cases each.

Woman in Group A received intravenous ferric carboxymltose $1000 \mathrm{mg}$ single dose in $250 \mathrm{ml}$ of $0.9 \%$ normal saline over 15 minute. In group B 50 women received intravenous iron sucrose in 5 doses of $200 \mathrm{mg}$ diluted in $100 \mathrm{ml}$ of $0.9 \%$ normal saline and infused over $20 \mathrm{~min}$ on alternate days Up to 5 days. Women having history of allergic reactions to previous parenteral iron 
therapy, megaloblastic anemia, aplastic anemia, thalassaemia, sickle cell anaema, $\mathrm{H} / \mathrm{o}$ asthma, allergy, patient with anaemia due to chronic illness like liver disease, renal disease and infections were excluded from the study.

Total dose calculation for iron deficit is given below:

Total iron dose required $(\mathrm{mg})=2.4 \mathrm{x}$ Bodyweight (in Kg) $x$ (Target $\mathrm{Hb}$ - Actual Hb in gm/dl) + 500mg.

The factor 2.4 is derived from the blood volume which is $7 \%$ of body weight and iron content of $\mathrm{Hb}$, which is $0.34 \%$ $(0.07 \times 0.0034 \times 100=2.4 \mathrm{mg}) \quad$ (Conversion from $\mathrm{gm} / \mathrm{dlto} \mathrm{mg}$ ).

\section{Results and Discussion}

In the present study cases selected in both the groups were comparable in terms of age, parity and socioeconomic status. Total 100 antenatal women between 28-34 wks of gestation were included in the study, 50 cases in each group. Mean age of antenatal women included in our study was $25.2 \mathrm{yrs}$, mean parity was 2 or more and mean gravidity was $4+\_3$ as ( table 1). Majority of the cases belonged to lower middle class(class 4) according to Modified B.J.Prasad classification in both groups. Cases were randomly given injection ferric carboxymaltose and iron sucrose. Antenatal women in Group A (FCM group) were given injection ferric Carboxymaltose and in Group B (iron sucrose group) injection sucrose was given after informed consent.

In our study in group A, 41 women had moderate anemia and 9 had severe anaemia and in group B, 43 women had moderate anemia and 7 women were severely anaemic. In both groups combined $84 \%$ women had moderate anemia and $16 \%$ had severe anemia. Most of the women presented with anaemia at mean haemoglobin 8. Blood parameters was done before infusion and repeated 4 wks after infusion.

In group A preinfusion mean hemoglobin in was $9.02 \mathrm{gm} / \mathrm{dl}$, and after infusion mean hemoglobin was $11.48 \mathrm{gm} / \mathrm{dl}$. The increase of mean hemoglobin was $2.48 \mathrm{gm} / \mathrm{dl}$, 4 wks after infusion of ferric carboxymaltose .(Table II). In group Bpre infusion mean hemoglobin was $9.06 \mathrm{gm} / \mathrm{dl}$ and 4wks after infusion mean hemoglobin was $11.40 \mathrm{gm} / \mathrm{dl}$. The increase of mean hemoglobin concentration 4 wks after the infusion was $2.34 \mathrm{gm} / \mathrm{dl}($ Table II). Table IV depicted that postinfusion increase in hemoglobin concentration was slightly more in Group A. It was 11.48 in Group A and 11.40 in Group B. It is slightly more $(0.14 \mathrm{gm} / \mathrm{dl})$ in Group A.Both group significantly showed improvement in other blood parameters after Infusion. All adverse reactions are presented in Table V. No serious adverse effects were recorded in any of the women receiving infusion. Pain at injection site was more in Group B in 4 women while in Group A only 2 women complained of pain at injection site (Table V). 1 women in Group A \& 4 women in Group B required medication for nausea and vomiting (Table V).

In India many women with Iron deficiency anemia present late in pregnancy o at this gestation age (in third trimester) it is difficult to achieve the desired hemoglobin level with oral supplementation in moderate and severe anemia. To overcome this problem IV iron preprations (e.g iron dextran, iron sucrose, ferric carboxymaltose) are given. Now a days iron dextran is not used because of side effects, iron sucrose has to be given multiple injections to achieve desired haemoglobin. FCM is easy 
to administer by giving a single dose injection in comparison to multiple small dose injections of iron sucrose. Ferric carboxymaltose infusion significantly increased hemoglobin level and other blood parameters. The incidence of adverse effects was also lowered in group A.No risk of adverse drugs effects on higher iron dose of FCM in comparison to multiple small doses of Iron sucrose.FCM can be used on outpatient basis and women monitored for $1 \mathrm{hr}$ post procedure to ensure maximum safety observation and monitoring.FCM is well tolerated in pregnancy with fewer side effects. Single dose administration reduces the frequency of hospital visit. FCM represents a novel iron preparation that overcome limitations of existing i.v preparations, is effective in correction of $\mathrm{Hb}$ deficit and rapidly replenish the iron stores.(9)

To date no perspective Controlled clinical study has been performed using ferric carboxymaltose in pregnant women. A recent Cochrane review concluded that large good quality trails, assessing clinical outcomes(including side effects) as well as the effects of treatment by severity of anemia are required.(10)In this study FCM \& Iron sucrose both increases the haemoglobin level and other blood parameters significantly. Very few studies are available regarding the use of intravenous ferric carboxymaltose in pregnancy. So we need large good quality trials to assess clinical outcomes including the adverse effects as well as the effect of treatment by severity of anaemia are required (10). As unavailability of studies, observations may help regarding safety efficacy and potential health benefits and risk. Two recent retrospective observational studies comparing ferric carboxymaltose to different iron preparation highlightened the safety and efficacy of FCM.Gionnoulis et al. reported increase of haemoglobin by 4-6 $\mathrm{gm} / \mathrm{dl}$ in 4 wks in patient receiving iron sucrose, whereas in our study increase in haemoglobin 4 wks after iron sucrose is 2.10 $\mathrm{gm} / \mathrm{dl}(11)$.In our study increase in mean haemoglobin is $2.48 \mathrm{gm} \%$ after 4 weeks in patient with FCM and $2.10 \mathrm{gm} \%$ in patient with Iron sucrose. Rise in haemoglobin was associated with increase of all other parameters significantly. Our results validate several randomized, controlled, multicenter trials in pregnancy and post partum patients where FCM was considered to be very effective in the treatment of anaemia. Adverse effects were $16 \%$ in group A and $20 \%$ in group B. In group A pain at injection site $(0 \%)$, breathlessness $(4 \%)$, transient hypotension( $4 \%$ ), headache( $2 \%)$, skin rash in $(2 \%)$, urticaria( $2 \%)$, nausea \& vomiting in $(2 \%)$. Pain at injection site was common adverse effect in patient with group B (8\%), followed by transient hypotension $(6 \%)$, nausea \& vomiting reported in ( $1 \%)$. All the patients had uneventful recovery after receiving treatment.

In a prospective study by frossler et al(12 ) intravenous ferric carboxymaltose infusion significantly increased haemoglobin level $(\mathrm{p}<0.01)$ above baseline levels in all women. Increase in haemoglobin and serum ferritin level 3 \& 6weeks after infusion and upto 8 weeks post infusion. Van wynk et. $\mathrm{Al}(13)$ reported increase in mean haemoglobin $2 \mathrm{gm} \%$ in 7 days and $3 \mathrm{gm} \%$ in 3-4 weeks in patient receiving FCM during postpartum period. Other baseline parameters were also significantly higher in FCM group as compare to Iron sucrose group.

In our study on postpartum women it was found that mean hemoglobin level and the rate of increase in hemoglobin level was significantly higher in patients receiving intravenous iron carboxymaltose during postpartum period. ${ }^{14}$ 
Int.J.Curr.Res.Aca.Rev.2016; 4(2): 124-130

Table.1 Demographic Profile of Women Given Iron Preparations

\begin{tabular}{|c|c|c|c|c|c|c|c|c|c|c|c|c|c|c|c|c|}
\hline S. N. & V & $\mathbf{a}$ & 1 & $\mathbf{i}$ & & $\mathbf{a}$ & b & 1 & $\mathbf{e}$ & $\mathbf{S}$ & $\mathbf{M}$ & e $\mathbf{a}$ & $\mathbf{n}$ & \pm & & D \\
\hline 1 & $\mathrm{~A}$ & $\mathrm{~g}$ & $\mathrm{e}$ & ( & $\mathrm{y}$ & $\mathrm{e}$ & $\mathrm{a}$ & $\mathrm{r}$ & $\mathrm{s}$ & ) & 25 & & 2 & \pm & 6 & 8 \\
\hline 2 & $\mathrm{G}$ & & : & $\mathrm{a}$ & & V & $\mathrm{i}$ & & 1 & $\mathrm{a}$ & 4 & & & \pm & & 3 \\
\hline 3 & $\mathrm{~Pa}$ & & & & & & & & & & 2 & & & \pm & & 2 \\
\hline 4 & & tior & $1 \mathrm{age}$ & vks) & & & & & & & 3 & & & & & 3 \\
\hline 5 & & $\log$ & bin le & el (Pr & $\overline{\inf }$ & sion) & & & & & & & & 8 & & \\
\hline
\end{tabular}

Table.2 Comparison of Blood Parameters before and after Drug Intervention in Group A (Fem Group)

\begin{tabular}{|c|c|c|c|c|c|}
\hline \multirow[t]{2}{*}{ S. N. } & \multirow[t]{2}{*}{ Blood Parameters } & $\begin{array}{lll}\text { F } & \text { C } & \text { M } \\
\end{array}$ & $\begin{array}{lllll}\mathbf{G} & \mathbf{r} & \mathbf{0} & \mathbf{u} & \mathbf{p}\end{array}$ & \multirow[t]{2}{*}{ P-value } & \multirow[t]{2}{*}{ z-value } \\
\hline & & 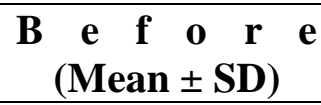 & 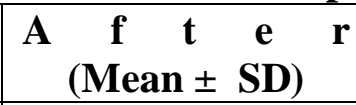 & & \\
\hline 1 & Haemoglobin (gm\%) & $9.02 \pm 0.8$ & $11.48 \pm 0.6$ & 0.001 & 17 \\
\hline 2 & $\mathrm{RBC}(\mathrm{mCell} / \mathrm{s} / \mathrm{cmm})$ & $3.50 \pm 0.4$ & $4.01 \quad \pm \quad 0.4$ & 0.001 & 37 \\
\hline 3 & $\begin{array}{lll}\mathrm{P} & \mathrm{C} & \mathrm{V} \\
\end{array}$ & $28.92 \pm 3.4$ & 33.76 & 0.001 & 7 \\
\hline 4 & M C V ( f 1/d l $)$ & $78.63 \pm 9.6$ & 82.10 & 0.04 & 0 \\
\hline 5 & $\mathrm{MCHC}(\mathrm{g} \mathrm{m} / \mathrm{dl})$ & 30.09 & 33.18 & 0.001 & 6 \\
\hline 6 & $\mathrm{MCH}(\mathrm{pg} / \mathrm{d} 1)$ & 26.75 & 28.80 & 0.01 & 5 \\
\hline 7 & $\mathrm{~T}$ & $6653.72 \pm 279.6$ & $5289.60 \pm 257.4$ & 0.001 & 25 \\
\hline 8 & Platelet Count & $242.16 \pm 82.6$ & $228.87 \pm 69.2$ & 0.38 & 87 \\
\hline
\end{tabular}

Table.3 Comparison of Blood Parameters before and after Infusion in Group B (Iron Sucrose Group)

\begin{tabular}{|c|c|c|c|c|c|}
\hline S. N. & Blood Parameters & $\begin{array}{c}\text { B } \underset{(M e a n}{\text { e f }} \pm \mathbf{S D}) \\
\mathbf{r} \text { e }\end{array}$ & 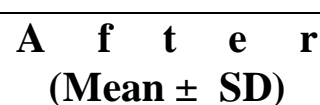 & z-value & P-value \\
\hline 1 & aemoglobin $(\mathrm{gm} \%)$ & $9.06 \pm 0.7$ & $11.40 \pm 0.8$ & 15.56 & $\begin{array}{llllll}0 & 0 & 1\end{array}$ \\
\hline 2 & $(\mathrm{mCell}$ & $3.69 \pm 0.3$ & $3.79 \pm 0.4$ & 1.41 & .16 \\
\hline 3 & $\mathrm{~V}$ & $28.12 \pm 2.1$ & $32.40 \pm 2.7$ & 8 & $\begin{array}{llll}0 & 0 & 1\end{array}$ \\
\hline 4 & M C V ( f l l / d l $)$ & $82.69 \pm 2.2$ & 84.48 & 7 & $\begin{array}{llllll} & 0 & 1\end{array}$ \\
\hline 5 & $\mathrm{MCHC}(\mathrm{g} \mathrm{m} / \mathrm{d} \mathrm{l})$ & $33.02 \pm 1.8$ & 32.94 & 0 & .80 \\
\hline 6 & $\mathrm{MCH}(\mathrm{pg} / \mathrm{d} \mathrm{l})$ & $31.28 \pm 1.6$ & 32.04 & 3 & 0 \\
\hline 7 & & $5890.64 \pm 33.6$ & $5651.20 \pm 206.7$ & 0 & 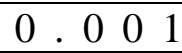 \\
\hline 8 & Platelet Count & $296.04 \pm 84.9$ & $259.18 \pm 93.6$ & 0 & $\begin{array}{llll}0 & 0 & 4\end{array}$ \\
\hline
\end{tabular}


Int.J.Curr.Res.Aca.Rev.2016; 4(2): 124-130

Table.4 Comparison of Blood Parameters B/W Two Group after Infusion

\begin{tabular}{|c|c|c|c|c|c|}
\hline \multirow[t]{2}{*}{ S. N. } & \multirow[t]{2}{*}{ Blood Parameters } & FCM Group & Iron sucrose group & \multirow[t]{2}{*}{ z-value } & \multirow[t]{2}{*}{ P-value } \\
\hline & & $\begin{array}{c}\text { B } \underset{(M e a n}{\text { e }} \pm \text { f } \\
(\text { SD })\end{array}$ & $\begin{array}{l}A \underset{(M e a n}{f} \pm \text { SD }) \\
\end{array}$ & & \\
\hline 1 & Haemoglobin $(\mathrm{gm} \%)$ & $11.48 \pm 0.6$ & $11.40 \pm 0.8$ & 5 & .5 \\
\hline 2 & $\mathrm{RBC}(\mathrm{mce} 11 \mathrm{~s} / \mathrm{cmm})$ & $4.01 \pm 0.4$ & $3.79 \pm 0.4$ & 7 & 007 \\
\hline 3 & $\begin{array}{lll}\mathrm{P} & \mathrm{C} & \mathrm{V} \\
\end{array}$ & $33.76 \pm 3.0$ & $32.40 \pm 2.7$ & 2 & . 02 \\
\hline 4 & $\mathrm{MC} \mathrm{V}(\mathrm{f} / \mathrm{l} / \mathrm{d} 1)$ & $82.10 \pm 7.2$ & $84.48 \pm 2.3$ & 2 & 0 \\
\hline 5 & $\mathrm{MCHC}(\mathrm{g} \mathrm{m} / \mathrm{d}$ l $)$ & $33.18 \pm 3.2$ & $32.94 \pm 1.5$ & 0 & 0 \\
\hline 6 & $\mathrm{MCH}(\mathrm{p} g / \mathrm{d} \mathrm{l})$ & $28.80 \pm 4.1$ & $32.04 \pm 1.6$ & 5 & $\begin{array}{llll}0 & 0 & 1 \\
\end{array}$ \\
\hline 7 & $\mathrm{~T} \quad \mathrm{C}$ & $5289.60 \pm 257.4$ & $5651.20 \pm 206.7$ & 7 & $\begin{array}{llll}0 & 0 & 1 \\
\end{array}$ \\
\hline 8 & Plate 1 e t & $228.87 \pm 69.2$ & $259.18 \pm 93.6$ & 1 & . 62 \\
\hline
\end{tabular}

Table.5 Adverse Drug Reactions

\begin{tabular}{|c|c|c|c|}
\hline S. N. & L o c a l R e a c t i o n $s$ & FCM Group & Iron Sucrose Group \\
\hline 1 & Injection site Pain & 0 & 4 \\
\hline 2 & B reathles $\mathrm{s} n$ e $s$ s & 2 & 2 \\
\hline 3 & $\begin{array}{lllllllllll} & a & \text { l } & \text { p } & \text { i } & \text { t } & \text { a } & \text { t } & \text { i } & \text { o } & \text { n }\end{array}$ & 0 & 0 \\
\hline 4 & $\begin{array}{llllllll}\mathrm{S} & \mathrm{w} & \mathrm{e} & \mathrm{a} & \mathrm{t} & \mathrm{i} & \mathrm{n} & \mathrm{g}\end{array}$ & 0 & 1 \\
\hline 5 & 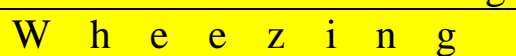 & 0 & 0 \\
\hline 6 & Transient hypotension & 2 & 3 \\
\hline 7 & 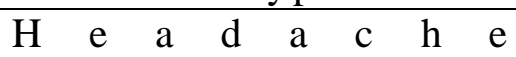 & 0 & 0 \\
\hline 8 & $\mathrm{Nausea}$ Vomiting & 1 & 1 \\
\hline 9 & $\begin{array}{llllllll}\mathrm{S} & \mathrm{k} & \mathrm{i} & \mathrm{n} & \mathrm{r} & \mathrm{a} & \mathrm{s} & \mathrm{h}\end{array}$ & & \\
\hline 0 & 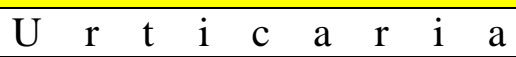 & 1 & 0 \\
\hline
\end{tabular}

Thus FCM is easy to administer by giving single dose injections as comparison to multiple small dose injection of iron sucrose. No risk of of adverse effect on higher IV dose of FCM in comparison to multiple small injection of iron sucrose. FCM can be used on outpatient basis and women monitored for one hour post procedure to ensure maximum safety observation and monitoring.FCM is well tolerated in pregnancy with fewer side effects. Single dose administrate reduces the frequency of hospital visit.

To date no perspective, controlled clinical study has been performed using ferric carboxymaltose in pregnant women. A recent cochrane review concluded that large good quality trials, assessing clinical outcome (including side effects) as well as the effects of treatment by severity of anaemia are required.

\section{Conclusion}

To date from the prospective study is consistent with other studies that ferric carboxy maltose administration in the second and third trimester of pregnancy is likely to be safe and effective the mean haemoglobin level achieved in the intravenous iron ferric carboxy maltose was significantly higher than iron sucrose group the simple FCM dosing regime was associated with greater patient compliance compared with iron sucrose. Large single 
dose of delivery of FCM is promising treatment modality in pregnant women with anaemia over other iron preparations in which multiple doses are required thus FCM reduces the burden on patients and health care systems to have multiple hospital visits and reduces the need of blood transfusion.

\section{References}

Bernd Froessler,Joshua Collingwood, Nicolette A Hodyl,Gustaaf Dekker. Intravenous ferric carboxymaltose for anaemia in pregnancy. BMC pregnancy and Childbirth 2014; 14(115).

Bodnar LM, Siega-Riz AM, Miller WC, Cogswell ME, McDonald T. Who should be screened for postpartum anemia? An evaluation of current recommendations. Am J Epidemiol 2002, 156(903-12).

Erin McLean, Ines Egli and Mary Cogswell. WHO global database on anemia . 2008.

Giannoulis C, Daniilidis A, Tantanasis T, Dinas K, Tzafettas J. Intravenous administration of iron sucrose for treating anemia in postpartum women. Hippocratia. PMC free article 2009; 13(38-40).

M Ezzati, AD Lopus, A Dogers, HS Vander, C Murray. Selected major risk factors and global and regional burden of disease.Lancet 2002 Nov 2; 360 (9343)(1347-1360): 18.

Micronutrient Profile of Indian Population. Indian Council of Medical Research, New Delhi. 2004.
Micronutrient Profile of Indian Population. Indian Council of Medical Research,New Delhi. 2004.

National Family Health Survey. .http://www.nfhsindia.org/pdf/India.pdf, 2005-2006.

National Nutrition Monitoring Bureau. NNMB Micronutrient Survey. National Institute of Nutrition Hyderabad 2002 .

Pfenniger A, Schuller C, Christoph P, Surbek D. Safety and efficacy of high dose intravenous iron carboxymaltose vs. iron sucrose for treatment of postpartum anemia. $J$ perinat Med 2012 April-2; 40(4).

Public summary Document- Ferric Carboxymaltose, solution for I.V use, $500 \mathrm{mg}$ in $10 \mathrm{ml}$, Ferinject. Australian Government Department of Health. November-2013.

Reveiz L, Gyte Gillian ML, Cuervo Luis G, Casasbuenas A. Treatment for irondeficiency anaemia in pregnancy. In Cochrane Database of systematic Reviews. John Wiley \& Sons, Ltd 2011; (10).

Ruchika Garg, Saroj Singh, Shikha Singh, Renu Rajvanshi; A Comparative Study to Evaluate the Efficacy and Safety of Single Dose Intravenous Iron Carboxymaltose vs Multidose Iron Sucrose in Postpartum Cases of Severe Iron Deficiency Anemia; Journal of SAFOG 01/2015; 7(2):18-21

Van Wynk DB, Martens MG, Seid MH, Baker $\mathrm{JB}$, Masngoine A. Intravenous ferric carboxymaltose compared with oral iron in the treatment of postpartum anaemia, A randomized controlled trial. Obst Gynaecol 2007; 110(267-78).

\section{How to cite this article:}

Ruchika Garg, Asha Nigam, Prabhat Agrawal, Ashwini Nigam and Rachna Agrawal. 2016. Iron Carboxymaltose: A Safe and Effective Molecule to Combat Anemia in Pregnancy. Int.J.Curr.Res.Aca.Rev. 2016.4(2): 124-130. doi: http://dx.doi.org/10.20546/ijcrar.2016.402.015 